\title{
A Climate Diplomacy Proposal: Carbon Pricing Consultations
}

Adele C. Morris, Warwick J. McKibbin, and Peter J. Wilcoxen

February 2013

\section{Introduction}

Climate talks in December 2012 in Doha, Qatar, wrapped up lines of negotiation that were begun years before in Bali. Negotiators resolved contentious questions about the future of the Kyoto Protocol and finally put the constraints of the Bali agenda behind them. Now they will turn to developing by 2015 a new agreement under the United Nations Framework Convention on Climate Change (UNFCCC) to cover the post-2020 period. At the same time, the Major Economics Forum (MEF) needs a new thrust of engagement, having developed the Clean Energy Ministerial into an enduring venue for technology discussions. ${ }^{1}$ This momentary opening for new agenda items offers an excellent opportunity to expand the dialogue to include technical aspects of the one policy approach that would actually address the climate problem cost effectively: pricing carbon and other greenhouse gases (GHGs).

Negotiators should take this opportunity to establish a Carbon Pricing Consultation (CPC) process: a detailed, pragmatic, and ongoing discussion of the implementation details of domestic cap-andtrade and GHG taxes. A CPC process would address a glaring gap in climate talks to date. Negotiations have tackled national emissions targets, global temperature targets, technology transfer, assistance to poor countries for adaptation and mitigation (a.k.a. "finance"), clean energy, forest preservation, compensation for countries affected economically by mitigation measures, and many other topics. Carbon pricing, however, has received little multilateral attention. It has generally been considered to be a national-level policy-to be adopted at the discretion of individual governments-and therefore

1 The 17 major economies participating in the MEF are: Australia, Brazil, Canada, China, the European Union, France, Germany, India, Indonesia, Italy, Japan, Korea, Mexico, Russia, South Africa, the United Kingdom, and the United States.

Viewpoints present policy proposals, considered opinions, and commentary by distinguished policymakers, leaders from business and non-governmental organizations, and scholars. The Harvard Project on Climate Agreements does not advocate any specific climate change policy proposals. Statements and views expressed in Viewpoints are solely those of the authors and do not imply endorsement by Harvard University, the Harvard Kennedy School, or the Harvard Project on Climate Agreements. 
outside the purview of international talks. However, much could be gained by bringing countries together to discuss carbon pricing. A CPC process would provide an opportunity for negotiators, as well as the administrators of national pricing policies, to discuss how to induce, practically and efficiently, the broad economic shifts required to de-couple emissions and economic activity.

Why focus on carbon pricing? A carbon price, arising either via a cap-and-trade market or a carbon tax, creates broad, efficient incentives to reduce greenhouse-gas emissions. Done well, it would gradually shift consumer demand, production methods, new investment, and technology development towards less emissions-intensive goods and services without unduly burdening poor households. A carbon tax or auctioned cap-and-trade allowances can also raise revenue to fund government outlays or reduce other, more distortionary, taxes. Finally, a carbon price can promote economic growth by replacing less efficient tax, regulatory, and spending policies. For these reasons, there is nearly universal agreement among economists that a price on carbon is a highly desirable step for reducing the risk of climatic disruption. Most would also agree that to be effective in the long run, any significant carbon policy will have to involve a price signal.

Why international consultations? First, outside of finance issues, few countries have sufficiently included their finance and trade ministries in climate negotiations. Thus the perspectives and expertise most familiar with the economics of market-based emissions approaches have been missing in the talks. Second, many countries have recently adopted carbon pricing policies, so there is increasing experience to analyze and discuss. Third, some countries that have not yet adopted carbon prices, such as the United States, have considerable expertise in efficient administration of excise taxes and could provide valuable advice. Fourth, talks to date have focused on emissions targets, both collectively and by country, divorcing the dialogue from the economic realities of achieving those commitments. It is much easier to reach consensus on the goal of containing global mean temperature increases to 2 degrees centigrade than to grapple with the potentially high price signals on carbon that would be necessary globally to achieve the goal. Until negotiators directly address the levels of economic effort involved and how to minimize the cost, collective commitments to stabilization targets will remain both theoretical and infeasible, however compelling they may be scientifically. Fifth, disparate carbon prices across different countries can shift emissions, production, investment, and trade patterns, and mutual understanding of these cross-border effects is of interest to all parties. Finally, the vehement opposition to the EU's efforts to price carbon in aviation fuels suggests that unilateral approaches to carbon pricing can undermine cooperation and climate policy progress. Not 
least, it shows the critical relationship between carbon pricing and international commerce and bolsters the case that this topic is a natural basis for a new climate diplomacy.

\section{Towards Carbon Pricing Consultations}

The international community should establish a CPC to provide a much needed place to discuss, laud, and understand efforts by countries to price greenhouse gases. It would differ from most talks under the United Nations Framework Convention on Climate Change (UNFCCC) in that the agenda would focus specifically on administrative, economic, and trade-related aspects of policies that price carbon and other GHGs. For example, discussions could include an exchange of countries' views, experience, and methodologies related to:

- how cap-and-trade and/or carbon tax systems work administratively;

- administration of excise taxes on carbon content of fuels, including ways to identify taxable entities, establish a tax base (emissions and sources), set reporting requirements for firms, track revenue, minimize administrative costs, and ensure compliance;

- ways to harmonize tax administration across countries to foster compliance by multinational firms and prevent tax gaps and double-taxation;

- the potential economic benefits to developing countries of carbon pricing as a low carbon growth strategy and efficient revenue instrument;

- the environmental and economic effects of alternative carbon tax levels and tax trajectories;

- mechanisms for managing allowance markets and registries, and distributing allowances or allowance auction proceeds;

- the design and implementation of border carbon adjustments;

- approaches to taxing carbon in bunker fuels;

- the feasibility of including non- $\mathrm{CO}_{2}$ gases, agriculture-and forest-related emissions, and process-related $\mathrm{CO}_{2}$ emissions in a carbon pricing system;

- the role of sub-national approaches;

- the macroeconomic and trade impacts of carbon pricing;

- the distributional effects of a price on carbon, such as effects on poor households or disproportional regional effects, and how to address them; 
- approaches to pricing carbon in imported and exported fossil fuels and closely-related products;

- experience with the environmental performance of carbon pricing;

- other fiscal reforms made in conjunction with carbon pricing (such as budget deficit reductions or reductions in other taxes), and their impacts;

- approaches to fiscal cushioning (such as reducing other energy taxes while establishing a price on carbon);

- how to report on carbon pricing policies so that measures can be compared across countries;

- the relationship between carbon pricing and other policies, such as energy efficiency standards and renewable energy subsidies; and

- efficient implementation of carbon pricing in large, complex, federalist systems.

The goal of these international discussions would be to build mutual comfort and confidence in carbon pricing, share views, prevent disputes and trade disruptions, identify and replicate successful approaches, learn from one another's mistakes, build institutional capacity, and generally promote mutual cooperation on serious, economically efficient, measures to mitigate emissions.

The CPC could also consider how to guide resources and activities of existing bilateral consultations, multi-lateral development banks, the Green Climate Fund, other institutions, and private sector entities towards efficient carbon pricing. One particular option could be to find ways to assist developing countries in their efforts to reduce fossil fuel subsidies and adopt a carbon tax or cap-and-trade program for greenhouse gases. For example, the U.S. Environmental Protection Agency already works with China's Ministry of Environmental Protection to build the institutions and infrastructure for sulfur dioxide cap-and-trade programs. ${ }^{2}$ And the Asian Development Bank currently assists its member countries in establishing and enforcing value-added taxes. The CPC could discuss whether multilateral technical support, either directly through member agencies or through regional development banks, could assist developing countries with similar measures for greenhouse-gas emissions trading and carbon excise taxes.

The CPC could also consider ways to enlist existing institutions for analytical support related to carbon pricing. For example, the International Monetary Fund recently issued a report on fiscal

2 For more, see EPA's Clean Air Markets website: http://www.epa.gov/airmarkt/international/china/index.html 
policy approaches to mitigate climate change that can help policymakers in its member countries think through the potential for a carbon tax. ${ }^{3}$ Likewise, the OECD has prepared an illuminating cross-country comparison of energy and carbon pricing approaches. ${ }^{4}$ The CPC could consider ways to expand or target efforts by these institutions to facilitate cooperation on climate change.

It may be possible-and it is desirable-to embed the CPC within the Major Economies Forum, the G-20, or other existing forums as much as feasible. The defining characteristic of the CPC, distinguishing it from existing clean energy and climate consultations, would be that the finance and trade ministries (not the environment and energy ministries) would take the lead. These are the ministries charged with international economic relationships, tax administration, and general macroeconomic stewardship. Of course, to the extent that environment or energy ministries oversee domestic carbon tax or cap-and-trade systems, they would play a role. However, the focus of the discussions would be on the technical, administrative, and economic cooperation aspects of carbon pricing policies, with minimal attention to whether any particular country's approach would achieve any particular emissions target or other goal. To that end, the typical level of engagement within the CPC may best lie below that of the ministerial level, and it should include those with technical expertise.

One advantage of this approach is that it would separate the work of the CPC, i.e. the pragmatic details of carbon pricing, from divisive issues such as who bears what responsibility for collective mitigation goals, who should compensate whom for what, and whose approach is more ambitious or moral. These debates, however important, have contributed little to global emissions mitigation. Subsequent or parallel efforts can review the adequacy of the price signals and seek to increase and/or harmonize them; the CPC should center on relatively low-profile but critically important administrative and technical policy exchanges by interested countries. An underlying premise is that most major emitters have a mutual interest in effective policy machinery to price carbon.

One useful outcome of the CPC dialogue could be to shape negotiations under the UNFCCC so that countries can supplement their emissions targets with commitments in the form of carbon pricing, allowing compliance by either achieving their emissions targets or by demonstrating

3 Fiscal Policy to Mitigate Climate Change: A Guide for Policymakers, edited by lan W.H. Parry, Ruud de Mooij, and Michael Keen, International Monetary Fund, 2012.

4 Taxing Energy Use: A Graphical Analysis, OECD Publication, January 28, 2013. 
significant effort through imposing agreed price signals. ${ }^{5}$ Price-based commitments would reduce the risk of inadvertent stringency or laxity, help achieve and document compliance, and allow Parties to compare their efforts transparently.

\section{Why a CPC is in the interests of the United States}

Consultations around mutual efforts to price carbon are clearly in the interests of countries that have already adopted or are seriously considering adopting such policies. However, even though the United States does not currently price carbon at the federal level, it would also benefit from carbon pricing consultations.

First, an increasing number of U.S. trading partners are adopting carbon pricing, and it is in the U.S. interest to follow these developments closely. Carbon taxes have been adopted in Sweden, Australia, Finland, Ireland, Norway, and South Africa, and the EU has a major $\mathrm{CO}_{2}$ emissions trading system. As mentioned above, India has a small tax on coal, and China is experimenting with cap-and-trade measures at the local and regional level for possible expansion nationwide. Canada also has several sub-national carbon pricing systems.

To be sure, the magnitude of the price signals and the scope of emissions to which they apply vary significantly across and within countries. But gradually more global fossil fuel consumption is falling under some sort of carbon pricing policy. The United States should welcome a venue in which it can learn from other countries' efforts, discuss potential economic spillovers and effects on international commerce, and foster discussions that could prevent international incidents such as the dispute over the EU aviation tax.

Second, the United States has considerable tax administration and cap-and-trade expertise that could highlight potentially successful approaches. Although this experience is not climate-related, the United States deploys an efficient and highly compliant excise tax system, and it could assist developing country efforts to build their own capacity to tax carbon. For example, the United States missed an opportunity to applaud and support India's recent adoption of a small tax on coal. The United States could offer to share its experience in administering its similar coal excise tax, which it collects under the Black Lung Benefits

5 McKibbin, Morris, and Wilcoxen (2012) outline just such an approach. http://www.brookings.edu/research/ papers/2012/07/carbon-tax-mckibbin-morris-wilcoxen. 
Act of 1977. The United States also has long experience with cap-and-trade systems for criteria air pollutants, much of which is transferable to greenhouse-gas emissions trading.

Finally, one key impediment to carbon pricing in the United States is the concern that if the United States prices carbon and other major emitters do not, then U.S. climate efforts will harm its economy to little environmental benefit. An international venue to discuss carbon pricing policies among major emitters could fruitfully evolve into a place to address such concerns and coordinate, if not fully harmonize, carbon price signals.

\section{Next Steps}

As a way forward, we recommend that at their next meeting this spring in Washington, MEF members discuss their preliminary views around the potential for carbon pricing consultations and options for CPC agenda items for future MEF meetings. Australia, given its experience in carbon pricing design, could also propose a CPC agenda item for the G-20 meetings that it will host in Brisbane next year. Discussions within the MEF and G20 could explore whether members believe a CPC agenda item would be productive within the UNFCCC process. 


\section{Adele C. Morris}

The Brookings Institution

\section{Warwick J. McKibbin}

\section{Australian National University}

The Brookings Institution

\section{Peter J. Wilcoxen}

Syracuse University

The Brookings Institution

\section{ACKNOWLEDGEMENTS}

The Harvard Project on Climate Agreements is grateful to the Harvard University Center for the Environment for generous current support. The Harvard Project also receives support from Christopher P. Kaneb (Harvard AB 1990); the James M. and Cathleen D. Stone Foundation; ClimateWorks Foundation; and the Qatar National Food Security Programme. The Project receives ongoing support from the Belfer Center for Science and International Affairs at the Harvard Kennedy School. The Project is grateful to the Doris Duke Charitable Foundation, which provided major funding during the period 2007 - 2010.

The closely affiliated, University-wide Harvard Environmental Economics Program receives additional support from the Enel Endowment for Environmental Economics at Harvard University, the Enel Foundation, the Alfred P. Sloan Foundation, the Mossavar-Rahmani Center for Business and Government at the Harvard Kennedy School, Bank of America, Chevron Services Company, Duke Energy Corporation, and Shell.

\section{ABOUT THE HARVARD PROJECT ON CLIMATE AGREEMENTS}

The goal of the Harvard Project on Climate Agreements is to help identify and advance scientifically sound, economically rational, and politically pragmatic public policy options for addressing global climate change. Drawing upon leading thinkers in Argentina, Australia, China, Europe, India, Japan, and the United States, the Project conducts research on policy architecture, key design elements, and institutional dimensions of international and domestic climate policy. The Project is directed by Robert N. Stavins, Albert Pratt Professor of Business and Government at the Harvard Kennedy School.

Project Email: climate@ harvard.edu

Project Website: http://belfercenter.hks.harvard.edu/climate 